\title{
La sociedad del espanto. Mallas de vidas en cuarentena
}

The society of astonishment. Meshwoks of lives quarantined

\section{Octavio Bonet ${ }^{1}$}

https://orcid.org/0000-0002-9742-2968

octavio.bonet@gmail.com

I Universidade Federal do Rio de Janeiro - Rio de Janeiro, RJ, Brasil 


\title{
Resumen
}

La pandemia del virus Covid-19 tiene el efecto paradójico de ponernos en una situación completamente nueva para el mundo moderno y, al mismo tiempo, movilizar conceptos que conocemos desde hace mucho tiempo. El objetivo de este artículo es proponer que la pandemia del coronavirus explicitó el entramado del mundo y al hacerlo nos transformó en lo que llamo la "sociedad del espanto" habitada por una nueva subjetividad que se caracteriza por la figura de los "nuevos heridos", desarrollada por Catherine Malabou. A través de establecer asociaciones entre Mauss, Bateson e Ingold se intenta entender las relaciones entre el hombre y el mundo como un conjunto entrelazado de líneas de vida, crecimiento y movimiento, que permite comprender las relaciones entre las dimensiones biológica, psicológica y social. Se propone pensar la pandemia y la cuarentena como un evento traumático a través de la cual se podría construir una nueva identidad colectiva e individual.

Palabras clave: antropología; subjetividad; pandemia; espanto.

\begin{abstract}
The COVID-19 virus pandemic has the paradoxical effect of putting us in a completely new scenario in the modern world and at the same time mobilizing concepts that we have known for a long time. The purpose of this article is to suggest that the coronavirus pandemic made explicit the entanglement of the world, but in doing so it transformed us into what I call the "society of astonishment" inhabited by a new subjectivity, characterized by the "new wounded" as conceived by Catherine Malabou. Through establishing associations between Mauss, Bateson and Ingold, an attempt is made to understand the relationships between man and the world as an interlocking set of lines of life, growth and movement, which allows us to understand the relationships between the biological, psychological and social dimensions. It is proposed to understand the pandemic and quarantine as a traumatic event through which a new collective and individual identity could be built.
\end{abstract}

Keywords: anthropology; subjectivity; pandemic; astonishment. 
La pandemia del virus Covid-19 tiene el efecto paradójico de ponernos en una situación completamente nueva para el mundo moderno y, al mismo tiempo, movilizar conceptos que conocemos desde hace mucho tiempo. En esta extraña situación que vivimos, encaja perfectamente la frase de Borges (1981, p. 279): "no nos une el amor, sino el espanto". El objetivo de este artículo es proponer que la pandemia del coronavirus explicitó el entramado ${ }^{1}$ del mundo y al hacerlo nos transformó en lo que llamo la "sociedad del espanto" habitada por una nueva subjetividad que se caracteriza por la figura de los "nuevos heridos".

El virus une pasado, presente y futuro en una trama de líneas a través de las cuales vamos experimentando nuevos afectos, repensando viejos conceptos y mirando perplejos lo que vendrá. Con la frialdad de lo Real (en el sentido lacaniano) $)^{2}$ el virus Covid-19 nos informa que no podemos separar la naturaleza de la cultura, que no podemos separar nuestra dimensión biológica de las dimensiones psicológica y social y que el mundo tiene su enmarañado como característica fundamental. De un plumazo, el virus cuestiona el núcleo de la modernidad.

Pero ya sabíamos todo eso. Sin embargo, como dice Gregory Bateson (1982), a veces es necesario repetir las perogrulladas porque se olvidan, ya que "todo el mundo lo sabe".

1 El concepto de malla, según Ingold, tiene como una de sus principales características configurarse como una maraña de líneas; de ese modo más que hablar de entramado, para respetar la idea del autor en este texto usaremos enmarañado y enmarañamiento al referirnos a esa propiedad de la malla.

2 No se trata de explicar en una nota a pie de página el concepto de Real en Lacan, sino de explicar en qué estaba pensando al referirme a la "frialdad de lo Real". Para Lacan, lo Real forma parte de la estructura psíquica del sujeto junto con lo Imaginario y lo Simbólico, representados en forma de nudo borromeo o de tres círculos enlazados. Lo Real, a diferencia de la realidad fenoménica, pertenece al orden de lo imposible, a lo que escapa a lo simbólico, al pensamiento. Es el límite, lo abyecto, que no está integrado. Es lo que no se puede aprehender directamente, pero que se alcanza a través de lo simbólico. Para Lacan, este Real, fuera del sentido, es "el objeto de angustia por excelencia" (Lacan, 1985). Cuando me refiero a la frialdad de lo Real, aludo a esa imposibilidad de sentido, pero que está ahí y por eso impulsa una búsqueda; es así como se puede asociar la falta de sentido con el espanto y con los debates en busca del sentido que ha proporcionado el virus. 


\section{Las mallas de vidas y las enseñanzas del virus}

La idea central del argumento que pretendo desarrollar está asociada al concepto de malla de Tim Ingold, entendido como un conjunto de líneas entrelazadas, como un enmarañado de líneas de vida, crecimiento y movimiento (Ingold, 2012a, 2015). Dos conceptos son fundamentales para la noción de malla de líneas de vida: el de medio ambiente y el principio de unión o correspondencia. El segundo se refiere a un entrelazamiento de devenires, a una respuesta mutua que se establece en este movimiento de seres "a través de" (Ingold, 2012a). La conceptualización del ambiente como zona de entrelazamiento se refiere a la ruptura de cualquier límite definido entre una supuesta interioridad del organismo y una supuesta exterioridad del mundo (Ingold, 2015). Esta última idea tiene como corolario la proposición de que las cosas se filtran, es decir, no son autocontenidas por la forma, sino en constante interacción con el ambiente (Ingold, 2012a).

Comencé el artículo diciendo cómo el virus vino a recordarnos el grado de enmarañamiento del mundo y cómo no podemos separar naturaleza y cultura. A lo largo de los meses impregnados por Covid-19, es posible leer numerosas publicaciones que se deslizan desde una dimensión molecular del virus -llamado enemigo invisible- a dimensiones molares, que hacen referencia a las dimensiones económica, social y política y sus consecuencias para las naciones. Lo micro y lo macro juntos resignificando múltiples costumbres tan cotidianas como el simple apretón de manos, un abrazo, y tan complejas como los distintos "arreglos de cuidado" (Fazzioni, 2018) con los que intentamos mitigar las consecuencias para nuestra salud y para la salud de las personas cercanas a nosotros.

Aunque la oposición naturaleza/cultura es fundamental para la tradición del conocimiento antropológico, ha sido cuestionada durante las últimas décadas. ${ }^{3}$ Así, el virus trajo la noticia de algo que ya sabíamos, pero que en cierto momento fuimos perdiendo de vista. Ingold sitúa este punto de inflexión en los siglos XVI-XVII junto con el proceso de modificación del acto de leer. En la Edad Media, la lectura era un acto continuo entre el texto y el lector, quien

3 No es el propósito de este artículo retomar este debate que, por su centralidad, tiene numerosos aportes. 
acompañaba la lectura con la mano ya que no había espacio entre las palabras. A finales del siglo XVII, el acto de leer se convirtió en una lectura con los ojos, no acompañada de la voz ni del gesto. Junto con este fenómeno, el texto pasa a dividirse en palabras y, en consecuencia, el libro de la naturaleza también se puede dividir en entidades discretas, que se pueden organizar en una taxonomía (Ingold, 2012b). Ese proceso de cambio subjetivo puede ser traducido diciendo que ganamos objetos (clasificables en taxonomías) y perdimos las relaciones entre ellos.

Esta última frase tiene fuertes resonancias con la obra de Gregory Bateson cuando escribe que en el momento en que perdemos la visión sistémica del mundo y comenzamos a guiarnos por propósitos conscientes, por fines en sí mismos, nos distanciamos de la dimensión del enmarañamiento, de los patrones que conectan y de las relaciones. Bateson llamó a este enmarañamiento de proceso mental, de vida o de espíritu. Y las características de estos sistemas nos permiten explicar tanto a los humanos como a los virus y los bosques (Bateson, 2000; Bateson; Bateson, 1989). En una conferencia que el autor dio en 1970, afirmó: “Tenemos ante nosotros un mundo que está amenazado no solo por las múltiples formas de desorganización, sino también por la destrucción de su ambiente, y nosotros, hoy día, somos incapaces de pensar claramente sobre las relaciones entre un organismo y su ambiente" (Bateson, 2000, p. 455). Para Bateson, el problema estaba en comprender qué era la unidad. En otras palabras, se preguntó: “¿qué evoluciona?” La unidad para él tenía que ser el hombre en su entorno; esa unidad formaba un proceso mental. Por lo tanto, cada uno de nosotros es una mente que está inmersa, y en retroalimentación, en una mente más amplia que Bateson llamó ecología planetaria (Bateson, 2000, p. 467).

En una tradición antropológica diferente, pero que también enfatiza las relaciones, se pueden mencionar dos artículos de Marcel Mauss, en los que desarrolla ideas muy pertinentes para el momento actual: La expresión obligatoria de los sentimientos, de 1921 (Mauss, 1974) y Las técnicas del cuerpo, de 1935 (Mauss, 2004b). Explicitando el concepto de "hombre total", Mauss dice que los sentimientos son expresiones colectivas, un lenguaje, por lo tanto, simbólicos. Pero para Mauss, además de signos y símbolos colectivos, los sentimientos son manifestaciones y distenciones orgánicas (trabaja específicamente con risas, lágrimas y gritos en los rituales funerarios). Por eso, para ser explicados, necesitan una perspectiva que junte Sociología, Psicología y Fisiología. 
En el artículo sobre las técnicas corporales retoma esta idea del triple punto de vista que permite explicar su perspectiva sobre los fenómenos corporales; los tres elementos que componen el "hombre total" tienen que estar "indisolublemente mezclados" (Mauss, 2004b, p. 405), por lo que habla de "ensambles fisio-psico-sociológicos".

El concepto de "hombre total" presente en los dos artículos mencionados se hace eco del concepto de hecho social total, desarrollado en el Ensayo sobre el don (Mauss, 2004a), texto de 1925, en el que Mauss conecta lo social y lo individual y los fenómenos sincrónicos y diacrónicos: “Todos estos fenómenos [que estudiamos] son a la vez legales, económicos, religiosos, e incluso estéticos, morfológicos, etc." (Mauss, 2004a, p. 309).

Los tres autores, Mauss-Bateson-Ingold, que seleccioné para construir el trípode que sustenta mi argumento se justifican por el énfasis en las relaciones que se encuentra en cada una de sus perspectivas teóricas. Aunque son de diferentes tradiciones antropológicas y de diferentes momentos históricos, creo que es posible incluirlos en una misma línea de pensamiento.

El diálogo que Ingold establece con Bateson, es más claro y explícito a través de su obra en numerosas referencias (Ingold, 2000, 2015), proximidad que fue explicitada por Velho (2001) y Bonet (2014) entre otros. Ingold (2015) establece fuertes relaciones entre su concepto de malla y el concepto de mente desarrollado por Bateson, mencionado anteriormente. Ambos autores realizan una transición de pensar en organismos-personas como entidades contenidas, para pensar en las relaciones y flujos entre ese organismo-persona y el ambiente. En Ingold, es posible percibir este cambio en las ideas de líneas abiertas y no cerradas y en el interés por vivir "a lo largo de" (Ingold, 2015, p. 147); y en Bateson en el énfasis en la mente como un sistema abierto o un circuito de autocorrección (Bateson, 1982, p. 174) o en lo que él consideraba un pasaje de la clasificación al proceso (Bateson, 1982, p. 171). De la misma forma, se puede encontrar en los textos de Ingold numerosas referencias a la obra de Mauss, especialmente al referirse al artículo sobre técnicas corporales (Ingold, 2015, p. 92, 103)

Creo que lo que permite establecer una línea de conexión entre Mauss, Bateson e Ingold es el interés compartido por el conocimiento transdisciplinar. $\mathrm{Y}$ a pesar de las diferencias de abordajes, los tres autores parten de una perspectiva que integra diferentes saberes para dar cuenta de los fenómenos 
estudiados. Por eso el énfasis en la interdisciplina o en la transversalidad de los campos del conocimiento.

Si Mauss abogaba por la necesidad de cooperación entre Sociología, Psicología y Fisiología, en los textos comentados anteriormente, Bateson pensaba en términos de grandes sistemas ecológicos y buscó los patrones que permitieran pensar tanto en las sociedades, los ecosistemas marinos o el mundo de la embriología. Finalmente, si Ingold comenzó interesado en proponer una transición de la complementariedad a la obviación (Ingold, 2001), lo que implicaba una forma diferente de pensar sobre la relación entre antropología, psicología y biología, actualmente está interesado en pensar en la relación entre lo que él llama cuatro "As": antropología, arqueología, arquitectura y artes (Ingold, 2013). La perspectiva de la obviación

tiene la intención de acabar con los límites por lo que estos componentes [biológicos, psicológicos y sociales] han sido caracterizados. Reivindica que el ser humano no es una entidad constituida por partes separadas mutuamente complementarias, como el cuerpo, la mente y la cultura, sino un locus único de crecimiento creativo dentro de un campo de relaciones que se desarrolla continuamente. (Ingold 2001, p. 256).

Se podría pensar que la perspectiva de la obviación sería un desarrollo que radicalizaría la línea de pensamiento presente en la propuesta de Mauss de las relaciones entre Sociología, Psicología y Fisiología, a la luz de los nuevos desarrollos en las tres disciplinas.

Considero que la perspectiva relacional que explicité en los tres autores trabajados reverbera en los debates actuales sobre las consecuencias de la pandemia y la cuarentena asociadas al Covid-19. En otras palabras, quiero decir que el virus ha venido a mostrar la necesidad de pensar lo molar y lo molecular juntos, las diferentes dimensiones de la persona asociadas a las dimensiones colectivas, sean económicas y/o políticas; sin embargo, el virus lo hace paradójicamente: nos muestra cómo estamos interconectados, enmarañados, separándonos y aislándonos en nuestros hogares.

El abordaje relacional presente en mi argumentación hace eco en el debate actual. Jérôme Baschet (2020a), en el texto Covid-19: el siglo XXI comienza ahora, retoma la idea de que la pandemia actual es "un hecho total en el cual 
la realidad biológica del virus es inseparable de las condiciones sociales y sistémicas de su existencia y difusión" (Baschet, 2020a). ${ }^{4} \mathrm{El}$ autor sostiene que la pandemia del Covid-19 no es la enfermedad del antropoceno, como se la había llamado, sino del capitaloceno: sistema histórico situado que tiene como características principales la maximización del beneficio y la inmediatez, que organiza el mundo según la economía y pone su énfasis en el interés privado y en el individualismo. Este sistema asociado a la globalización habría creado las condiciones para la posibilidad de una pandemia y se convirtió, según Baschet, en el verdadero enemigo.

La explicitación de este enmarañado del mundo señalada por los autores mencionados se evidencia en la proliferación de bichos, como dice Franco Berardi (2020b). ${ }^{5}$ Para él, en este proceso pandémico, el hombre habría perdido su centralidad:

El año 2020 debe verse como el año en el que la historia humana se disolvió, no porque los seres humanos desaparecieran del planeta Tierra, sino porque el planeta Tierra, cansado de la arrogancia humana, lanzó una microcampaña para destruir su "voluntad de poder". La Tierra se rebela contra el mundo, y sus agentes son las inundaciones, los incendios y, sobre todo, los bichos. (Berardi, 2020b).

Este desplazamiento del hombre hacia los bichos habla de una descentralización del hombre como agente de la evolución, de micro-flujos y de múltiples estrategias de proliferación. Para Berardi (2020b), este desplazamiento "es el fin de la subjetividad como motor del proceso histórico".

En la terminología de este texto, el desplazamiento en la centralidad del hombre explicita el enmarañamiento de relaciones, de líneas en las que siempre estamos involucrados, pero que olvidamos al perseguir los propósitos conscientes inmediatos, o al perseguir la maximización económica de vida.

4 Publicado originalmente en el periódico Le Monde, el 2 de abril de 2020 (Baschet, 2020b).

5 Berardi aclara en su texto que utiliza la noción de "bichos" en el sentido elaborado por Donna Haraway. El texto original de Berardi se publicó en inglés (Berardi, 2020a). 


\section{La sociedad del espanto y los nuevos heridos}

Si al principio del artículo la pregunta central era cómo el virus nos hizo retomar conceptos que ya conocíamos, ¿vale la pena preguntarnos por lo que no sabíamos?

Para empezar a dar respuesta a esta pregunta, me gustaría recordar el excelente libro de Claudine Herzlich y Janine Pierret (1991) titulado Malades d'hier, malades d'aujourd'hui en el que sostienen que cada época tiene un tipo de paciente y, por tanto, su enfermedad específica. El período de las epidemias en la Edad Media es el primer momento histórico que definen las autoras, en el que la enfermedad se asoció con la idea de número, impotencia, exclusión y muerte. La enfermedad era vivida por la sociedad en su conjunto, era un fenómeno colectivo. El segundo momento se caracterizaría por la aparición de la tuberculosis, en el siglo XIX, cuando se produce un cambio fundamental: la enfermedad dejará de ser un fenómeno de masas, pasando a ser un tema individual y una forma de vida. Con esta modificación surge el concepto moderno de 'enfermo': "la realidad e imagen de la enfermedad dejó de ser colectiva para ser la de un daño individual. El paciente es el individuo, sin que su vecino tenga nada que ver con él. Su enfermedad no es una advertencia ni una amenaza para su entorno. En su realidad orgánica, solo le concierne a él" (Herzlich y Pierret, 1991, p. 77). Con la transformación del enfermarse, que se vuelve individual y que va a provocar la muerte lentamente (la enfermedad como forma de vida), aparece el 'enfermo' como estatus y estigma. La contemporaneidad sería el momento de las enfermedades crónicas, en el que el paciente vive de forma individual y aislada su enfermedad asociada a su responsabilidad individual. El argumento se basaba en la noción de que las enfermedades epidémicas, aunque endémicas en algunas regiones del mundo, no representarían una amenaza para la humanidad.

Esta transformación de nuestro tiempo en el que las enfermedades crónicas son la prioridad, que nos involucran como individuos, permite introducir una de las posibles respuestas a la pregunta sobre el conocimiento. No sabíamos cómo vivir en una pandemia. No sabemos cómo lidiar con una cuarentena. No sabemos cómo lidiar con la proximidad diaria de la muerte. No es con una posible muerte en algún momento (que quizás sea la única certeza), sino con la noticia concreta y cotidiana de la muerte de personas conocidas o 
familiares. Esta es la nueva situación en la que nos ha puesto el virus. Aún no sabemos cómo afrontar las transformaciones subjetivas que impone la cuarentena. Hasta ahora las epidemias (ébola, cólera, H1N1 y otras) las sufrían otros, las crisis de migración masiva se veían en la televisión, pero el Covid-19 se ha expandido por el mundo, a pesar de las gigantes diferencias entre las diferentes regiones geopolíticas. El virus nos llegó, ahora forma parte de nuestra vida diaria. Y con eso, está en marcha una transformación de nuestra subjetividad.

El virus trajo un "miedo difuso" a la calle, a las cosas que vienen de la calle, a los abrazos y saludos. Espanto angustiado por las fotografías de ataúdes alineados. Quizás podríamos haber visto una imagen similar en algún momento, pero ahora esta visión macabra se asocia a la posibilidad de que nos pase a nosotros o a alguien próximo.

Quizás, precisamente porque vivimos en la era de las enfermedades individualizadas y de la medicina individualizada, no sabemos cómo vivir una epidemia. Quizás por eso estamos perplejos por la cuarentena y por el vacío de las calles provocado por esta amenaza invisible. A pesar de nuestro modelo de paciente, hoy nos enfrentamos a un nuevo virus que "paró al mundo". Quizás eso es lo que tampoco sabíamos: sobre la posibilidad o la necesidad de parar.

No es que no supiéramos sobre el aislamiento y la distancia para combatir una pandemia. Foucault (2011) en El nascimiento de la medicina social escribe que en la historia de la medicina occidental se desarrollaron dos modelos de organización médica: uno causado por la lepra y el otro por la peste. Desde la Edad Media, cuando un enfermo de lepra era identificado se lo expulsaba del espacio común, de las ciudades; es decir, el modelo era el de la exclusión y del exilio. El segundo modelo de organización fue el de la peste: en este caso el paciente no era expulsado, sino identificado. El poder político de la medicina, según Foucault (2011, p. 89) consistía en "distribuir a los individuos uno al lado del otro, aislarlos, individualizarlos, vigilarlos uno a uno, verificar el estado de salud de cada uno [...] fijar a la sociedad en un espacio que se escanea, se divide, se inspecciona...". El modelo de organización de la peste es el de la cuarentena, que se conoce desde la Edad Media, y que la medicina urbana del siglo XVIII ha perfeccionado y que ahora consiste básicamente en: quedarse en casa, dividir la ciudad en barrios y disponer de vigilantes en cada calle que realizarían los informes diarios. En otras palabras: aislamiento e información. Sabemos esto 
desde hace mucho tiempo, pero todavía, en medio de la epidemia de Covid-19, algunos todavía continúan discutiendo su efectividad. ${ }^{6}$

La sociedad del espanto que propongo en este artículo se inscribe en una serie de transformaciones que tendían su inicio en la sociedad de la disciplina propuesta por Foucault (1998). El autor francés propuso una sociedad disciplinar con sus fábricas, cárceles y asilos, que producía obreros, presos y locos con sus cuerpos dóciles, ajustados y disciplinados; sociedad que habría alcanzado su apogeo en el siglo XX. Posteriormente, Deleuze (1992) argumenta que esta sociedad modular de la disciplina estaría siendo reemplazada por la sociedad del control. Esta sería una sociedad de modulaciones, como un molde que se auto-modifica permanentemente, sería la sociedad de la empresa, de las sanciones sustitutivas, del salario por mérito, de la formación permanente, de la rotación rápida, del corto plazo. Es una sociedad de fronteras difusas, pero con GPS que permiten un control permanente de los movimientos.

Una tercera transformación es propuesta por Byung-Chul Han (2015) en el libro La sociedad del cansancio; ésta es una sociedad enfocada en el desempeño y en la productividad, y con eso genera depresivos y fracasados; individuos agotados por tener que ser ellos mismos, que "ya no pueden más poder". Para Han, la sociedad del cansancio se despliega en las prácticas de doping, en la estimulación cognitiva, en el exceso de positividad. Esta sociedad se referiría a un cansancio individualizado que borra el mundo. Sin embargo, Han (2015, p. 39) marca una salida a esta trampa del cansancio de la sociedad, que estaría asociada a otro tipo de cansancio que él llama cansancio fundamental, que le permitiría al hombre "un sosiego especial, un no-hacer sosegado... No consiste en un estado en que se agoten todos los sentidos, [sino que] permite el acceso a una atención totalmente diferente, de formas lentas y duraderas que se sustraen de la rápida y breve hiperatención". Se puede ver cómo las características de esta sociedad del cansancio son las del capitaloceno, según la propuesta de Basquet antes mencionada.

6 Aún se puede decir que Brasil tiene un sistema de prevención y atención de salud suficientemente organizado que se basó en la territorialización y la división de la ciudad en áreas y microáreas, llamado Programa Salud de la Familia, pero que fue desmantelado por el poder público en los años anteriores a 2020. 
Quizás esa era la discusión en la que estábamos cuando la pandemia de Covid-19 se extendió por todo el mundo y cambió toda la agenda; la pregunta ahora está implícita en frases como: "cuando termine la cuarentena...", o "cuando todo vuelva a la normalidad...", o "cuando descubramos la vacuna...". Pero surge la pregunta: ¿la nostalgia de estas frases se refiere a qué "normal"? ¿A qué mundo volveremos? ¿De nuevo corriendo para producir más y más hasta que sintamos que el cansancio nos obliga a parar? En esta nueva sociedad que va tomando forma, la muerte está presente a diario, invisible y posible. Esta situación nos deja absortos y asombrados. ¿Será que estamos mutando, como el virus y por el virus, en la sociedad del espanto? El virus nos lleva a un estado de espanto, nos está transformando en una sociedad de espanto.?

Aunque propongo la idea de una sociedad del espanto, no significa que todos estemos espantados de la misma manera, así como se puede pensar que la depresión es la enfermedad actual de la sociedad del cansancio, sin afirmar que todos nos tornamos depresivos; o que vivimos en la sociedad de las disciplinas, pero éstas no nos afectan a todos de la misma manera. Es innegable que la pandemia provocó una transformación de la vida cotidiana a nivel mundial, las fotografías de calles vacías en diferentes capitales del mundo, el recuento de muertos, las filas de fosas en los cementerios, los protocolos sanitarios, se convirtieron en el tema de nuestras conversaciones independientemente del idioma. Quizás se necesiten varios trabajos etnográficos que muestren, a diferentes escalas, cómo y por qué cada grupo reaccionó de una manera específica. La perspectiva de lo particular (Abu-Luhgod, 2018) debe caminar paralelamente a la dimensión del espanto colectivo que hemos vivido desde el inicio de la pandemia.

7 En el artículo titulado "Aprendiendo del virus", Paul Preciado (2020) afirma que la pandemia de Covid-19 puede ser una mala noticia o una gran oportunidad. Y que la cura y los cuidados necesarios para salir de esta pandemia solo pueden surgir de un proceso de transformación política, que implica nuevas formas estructurales de cooperación planetaria. Ya sabemos que el virus muta, a medida que avanzamos en la pandemia se descubren nuevas cepas, producto de cómo el virus cambia cuando se replica; en este sentido, si algo podemos aprender del virus, como quiere Preciado, es que debemos mutar. Preciado distingue un tipo de mutación forzada y una deliberada, podríamos decir que la mutación forzada es la transformación en la sociedad del espanto, pero sería necesario reapropiarse del proceso de mutación para “imaginar la revolución que viene" (Preciado, 2020). 
Se puede pensar en dos formas de entender este significante espanto. En un primer sentido, el espanto se refiere al estado de ánimo producido por la pandemia, con la vulnerabilidad asociada a ella, debido al número de muertos y a las tumbas abiertas. Es en este sentido que nos encontramos perplejos por la muerte que surge, que está presente.

Sin embargo, el espanto puede tener una pedagogía y renovar el compromiso del hombre con el mundo y esto lleva al segundo sentido del significante.

En el libro Estar vivo, Ingold (2015) sostiene que el mundo como fuente de espanto significa vivir cada momento mundano como si fuera el primero, sintiendo su pulso, preguntándose cómo es posible un mundo así. El espanto, en un mundo en formación, en perpetuo movimiento, se refiere a una apertura al mundo. Pero si el espanto nos abre al mundo, también nos deja vulnerables porque se ha roto la fantasía de una conexión entre el hombre y el mundo. En otras palabras, el mundo ha dejado de funcionar como lo conocíamos, por lo que debemos repensarlo. Es así como el espanto puede ser fuente de fuerza, resistencia y sabiduría, que Ingold asocia con ontologías animistas. De esta forma, el conocimiento científico se configuraría para retomar esta perspectiva, integrada por la observación, la participación y el compromiso (Ingold, 2012b).

¿Cuál sería la subjetividad característica de esta sociedad del espanto? Aún no lo sabemos, pero quizás una posible respuesta se pueda encontrar en la categoría de Catherine Malabou: los nuevos heridos. En el libro The new wounded: from neurosis to brain damage (Malabou, 2012), la autora define esta categoría para pensar los sujetos que sufrieron daño cerebral, por accidente o degenerativo, pero también incluye en esta categoría otros trastornos clásicos del psicoanálisis, como compulsivo, esquizofrénico, autista; los nuevos heridos serían sujetos que "se caracterizarían por perturbaciones emocionales que consisten en un mal funcionamiento de las señales afectivas necesarias para tomar decisiones" (Malabou, 2012, p. 10). Hay dos características que Malabou explicita que me interesan. La primera es que amplía la categoría de "nuevos heridos" para abarcar a todo paciente en shock, que, sin haber sufrido lesiones cerebrales, tiene su equilibrio emocional modificado por un evento traumático. Y, en ese sentido, todos somos susceptibles de convertirnos en nuevos heridos. Este tipo de transformación no solo es visible en lesiones cerebrales, sino también en sobrevivientes de guerras, ataques terroristas y todo tipo de opresión. Lo que aporta la perspectiva de Malabou es una extensión del trauma que enfatiza la 
porosidad entre el trauma orgánico y el trauma sociopolítico, sin embargo, este trauma es experimentado de manera diferente por los sujetos. Perspectiva que podría complementarse con la idea de la "distribución diferencial de la vulnerabilidad" propuesta por Judith Butler (2016), cuando la autora sostiene que si bien todos compartimos una vulnerabilidad o precariedad original, algunas vidas son pasibles de duelo y otras no lo son; en este sentido, la "condición precaria designa la condición políticamente inducida en la que ciertas poblaciones sufren de deficientes redes de apoyo social y económico y están expuestas de manera diferente a violaciones, violencia y muerte" (Butler, 2016, p. 46).

La segunda característica asociada a la conceptualización de los "nuevos heridos" es la noción de plasticidad. Para Malabou, la plasticidad se referiría tanto a la creación de la forma como a su destrucción. Refiriéndose a los sujetos que sufrieron daño cerebral, Malabou asocia los dos significados de plasticidad y argumenta que una nueva forma de identidad puede surgir de un evento traumático. Malabou denomina plasticidad destructiva a esta creación de forma a través de la destrucción.

Se puede pensar en la pandemia como ese evento traumático que permite construir una nueva identidad colectiva e individual. Quizás porque necesitamos darle sentido a este trauma, esta extraña situación que se dio en esta pandemia, es que se observa una vasta producción de conocimiento en diferentes vehículos, ya sean académicos o no. Como si estuviéramos comprometidos en un movimiento colectivo de buscar saber, de entender cómo afrontar la cuarentena, cómo afrontar el trauma asociado a la nueva configuración subjetiva.

\section{En conclusión: ¿Qué nos vino a decir el virus?}

Esta pregunta hace referencia al ensayo de Ingold (2012b) "Caminando con dragones: hacia el lado salvaje" cuando describe el fenómeno de la experiencia y cita un texto de Irving Hallowell en el que cuenta la historia del pájaro-trueno, al que pocos ven, pero que su existencia se reconoce por el sonido del trueno que emite cuando vuela. El mundo Ogibwa, dice Hallowell, está habitado por seres más-que-humanos que son interlocutores vitales para los humanos. En este sentido, el mundo Ogibwa "es políglota, un híbrido de voces mediante las cuales diferentes seres, en sus diferentes lenguajes, enuncian su presencia, 
se sienten y producen su efecto" (Ingold, 2012b, p. 21). En un relato contado a Hallowell, el hombre Ojibwa le preguntó a la mujer: “¿Escuchaste lo que dijo el trueno?", "No lo hice bien", respondió la mujer. Hallowell señaló que la respuesta es la misma que se le daría a un ser humano al que no comprendimos. Ingold interpreta que escuchar un trueno no es una cuestión de traducción, sino de empatía, de establecer una relación de comunión y afecto; es decir: "Significa abrirse al ser del otro" (Ingold, 2012a, p. 21). Y el hacerlo, nos permite retomar nuestro compromiso con el mundo de la vida.

¿Cómo abrirnos al otro o al mundo de la vida? Una posible respuesta se encuentra en el ensayo de Berardi (2020b) cuando pregunta: ¿qué necesitamos? Él responde que a la larga necesitamos una nueva cultura de ternura, solidaridad y frugalidad, una sociedad libre de las compulsiones de la acumulación y el crecimiento económico. Para Berardi (2020b), "la propagación masiva de la muerte que estamos presenciando en esta pandemia podría reactivar nuestro sentido del tiempo como un fruto, y no como un aplazamiento de la alegría". En la misma dirección, se dirige el pensamiento de Baschet cuando dice que la verdadera guerra no es contra el coronavirus, sino contra el imperativo categórico de la economía en beneficio de una buena vida para todos. El camino, dice Baschet, es "la preferencia por la intensidad alegre de lo cualitativo [...] [que] podría sumarse al cuidado de los lugares habitados y las interacciones del sistema vivo, a la construcción de lo común, al mutuo apoyo y a la solidaridad" (Baschet, 2020a).

Quizás, si podemos lograr una relación más comprometida con el mundo, si podemos "abandonarnos" para sentir los enmarañados de líneas de vida en las que todos estamos, en ese momento sea posible "entender" lo que vino a decir el coronavirus y que el espanto de la frase de Borges adquiera el segundo sentido del significante, que abre la posibilidad de volver a unir el hombre y el mundo.

\section{Referencias}

ABU-LUGHOD, L. A escrita contra a cultura. Equatorial, Natal, v. 5, n. 8, p. 193-226, 2018.

BASCHET, J. COVID-19: o século XXI começa agora. In: N-1 EDIÇÕES. Pandemia crítica (17). São Paulo: n-1 edições, 2020a. Disponible en: https://www.n-1edicoes.org/ textos/50. Acceso: 3 ago. 2020. 
BASCHET, J. Le XXIe siècle a commencé en 2020, avec l'entrée en scène du Covid19. Le Monde, Paris, 2 avril 2020b. Disponible en: https://www.lemonde.fr/idees/ article/2020/04/02/jerome-baschet-le-xxie-siecle-a-commence-en-2020-avec-1-entree-en-scene-du-covid-19_6035303_3232.html. Acceso: 3 ago. 2020.

BATESON, G. Espíritu y naturaleza. Buenos Aires: Amorrortu Editores, 1982.

BATESON, G. Step to an ecology of mind. Chicago: The University of Chicago Press, 2000.

BATESON, G.; BATESON, M. C. El temor de los ángeles. Barcelona: Gedisa, 1989.

BERARDI, F. Beyond the breakdown: three meditations on a possible aftermath. e-flux conversations, [s. l.], 1 Mar. 2020a. Disponible en: https://conversations.e-flux. com/t/beyond-the-breakdown-three-meditations-on-a-possible-aftermath-by-franco-bifo-berardi/9727. Acceso: 3 ago. 2020.

BERARDI, F. Para além do colapso: três meditações sobre um possível depois. In: N-1 EDIÇÕES. Pandemia crítica (51). São Paulo: n-1 edições, 2020b. Disponible en: https://www.n-1edicoes.org/textos/85. Acceso: 3 ago. 2020.

BONET, O. Itinerações e malhas para pensar os itinerários de cuidado. A propósito de Tim Ingold. Sociologia \& Antropologia, Rio de Janeiro, v. 4, n. 2, p. 327-350, 2014.

BORGES, J. L. Obra poética, 1923-1977. Madrid: Alianza Editorial, 1981.

BUTLER, J. Quadros de guerra: quando a vida é passível de luto?. Rio de Janeiro: Civilização Brasileira, 2016.

DELEUZE, G. Post-scriptum sobre as sociedades de controle. In: DELEUZE, G. Conversações: 1972-1990. Rio de Janeiro: Editora 34, 1992. p. 219-226.

FAZZIONI, N. H. Nascer e morrer no Complexo do Alemão: políticas de saúde e arranjos de cuidado. 2018. Tese (Doutorado em Antropologia) - Instituto de Filosofia e Ciências Sociais, Universidade Federal do Rio de Janeiro, Rio de Janeiro, 2018.

FOUCAULT, M. Vigiar e punir. 18. ed. Petrópolis: Vozes, 1998.

FOUCAULT, M. Microfísica do poder. Rio de Janeiro: Graal, 2011.

HAN, B. C. Sociedade do cansaço. Petrópolis: Vozes, 2015.

HERZLICH, C.; PIERRET, J. Malades d'hier, malades d'aujourd'hui. Paris: Payot, 1991.

INGOLD, T. The perception of the environment: essays in livelihood, dwelling and skill. London: Routledge, 2000. 
INGOLD, T. From complementarity to obviation: on dissolving the boundaries between social and biological anthropology, archaeology, and psychology. In: OYAMA, S.; GRIFFITHS, P. E.; GRAY, R. D. (ed.). Cycles of contingency: developmental systems and evolution. Massachusetts: The MIT Press, 2001. p. 255-279.

INGOLD, T. Trazendo as coisas de volta à vida: emaranhados criativos num mundo de materiais. Horizontes Antropológicos, Porto Alegre, ano 18, n. 37, p. 25-44, jan./jun. 2012a.

INGOLD, T. Caminhando com dragões: em direção ao lado selvagem. In: STEIL, C.; CARVALHO, I. C. M. (org.). Cultura, percepção e ambiente: diálogos com Tim Ingold. São Paulo: Terceiro Nome, 2012b. p. 15-29.

INGOLD, T. Making: anthropology, archaeology, art and architecture. London: Routledge, 2013.

INGOLD, T. Estar vivo: ensaios sobre movimento, conhecimento e descrição. Petrópolis: Vozes, 2015.

LACAN, J. O seminário: livro 2: o eu na teoria de Freud e na técnica da psicanálise. Rio de Janeiro: Jorge Zahar, 1985.

MALABOU, C. The new wounded: from neurosis to brain damage. New York: Fordham University Press, 2012.

MAUSS, M. A expressão obrigatória dos sentimentos. In: MAUSS, M. Ensaios de sociologia. São Paulo: Perspectiva, 1974. p. 325-335.

MAUSS, M. Ensaio sobre a dádiva. Forma e razão da troca nas sociedades arcaicas. In: MAUSS, M. Sociologia e antropologia. São Paulo: Cosac Naify, 2004a. p. 183-319.

MAUSS, M. As técnicas do corpo. In: MAUSS, M. Sociologia e antropologia. São Paulo: Cosac Naify, 2004b. p. 399-422.

PRECIADO, P. B. Aprendiendo del vírus. El País, [s. l.], 28 mar. 2020. Disponible en: https://elpais.com/elpais/2020/03/27/opinion/1585316952_026489.html. Acceso: 9 feb. 2020.

VELHO, O. De Bateson a Ingold: passos na constituição de um paradigma ecológico. Mana, Rio de Janeiro, v. 7, n. 2, p. 133-140, out. 2001.

Recebido: 30/08/2020 Aceito: 01/02/2021 | Received: 8/30/2020 Accepted: 2/1/2021 